\title{
TLR3 Plays Significant Roles against HBV-Associated HCC
}

\author{
Xiao-lan Chen, ${ }^{1}$ Yu-yin Xu, ${ }^{1}$ Li Chen, ${ }^{2}$ Gui-lan Wang, ${ }^{2}$ and Yin Shen ${ }^{2}$ \\ ${ }^{1}$ Department of Nephrology, Affiliated Hospital of Nantong University, Nantong, Jiangsu 226001, China \\ ${ }^{2}$ Department of Pathological Anatomy, Nantong University, Nantong, Jiangsu 226001, China \\ Correspondence should be addressed to Li Chen; bl1@ntu.edu.cn
}

Received 28 July 2014; Revised 13 November 2014; Accepted 13 November 2014

Academic Editor: Zhongxia Wang

Copyright (c) 2015 Xiao-lan Chen et al. This is an open access article distributed under the Creative Commons Attribution License, which permits unrestricted use, distribution, and reproduction in any medium, provided the original work is properly cited.

\begin{abstract}
Toll-like receptor 3 (TLR3) is a pattern-recognizing receptor that is involved in immune signaling and plays a crucial role in survival by being able to recognize various viral components including double-stranded RNA (dsRNA). The role of TLR3 in hepatocellular carcinoma (HCC) with hepatitis B virus (HBV) infections is not well understood. To investigate the ability of TLR3 in regulating HBV replication in HCC, 80 cases of human HCC were collected and their tissue microarray was made. In HCC cells, the expression and location of TLR3, hepatitis-associated virus, and interstitial immunoreactive cells were assayed with immunohistochemical staining. The apoptosis of tumor cells was also detected by TUNEL stain. Correlations between TLR3 expression and HBV infection, interstitial immunoreactive cells, and cells apoptosis in HCC were investigated. In addition, we explored whether TLR3 agonist dsRNA can inhibit HepG2.2.15 cells secreting HBV. We found that the cytoplasmic expression of TLR3 in HCC is positively related to HBsAg infection and HCC with cirrhosis and promotes interstitial immunoreactive cells infiltration and cancer cells apoptosis. In HepG2.2.15 cells, dsRNA inhibited the secretion of HBV and induced apoptosis. These results indicate that TLR3 signaling activity may be involved in immune responses against HBV in HCC.
\end{abstract}

\section{Introduction}

Hepatocellular carcinoma (HCC) is one of the most prevalent malignant tumors and a leading cause of cancer-related deaths globally $[1,2]$. In recent studies conducted in Asia and Northern America, the estimated risk of developing HCC was observed to increase by $25-37$-fold in hepatitis B surface antigen (HBsAg) carriers compared with noninfected patients $[3,4]$. HBV frequently causes liver inflammation, hepatic damage, and subsequent cirrhosis. The development of liver cirrhosis is recognized as a major step in HCC pathogenesis because it occurs in $80 \%-90 \%$ of HCC [5]. To further investigate the clinical features of HBV-infected HCC and develop more effective therapeutic strategies, considerable efforts have recently been exerted in exploring the molecular mechanisms involved in the development and progression of HBV-associated HCC. Previous studies demonstrated that $\mathrm{T}$ cells, NK cells, and antigen-presenting cells (APC) inhibit HBV replication when they are activated by alpha-galactosylceramide, interleukin-12 (IL-12), IL-18, and an agonistic anti-CD40 antibody injection, respectively
$[6,7]$. Collectively, these results suggest that HBV replication can be controlled by innate immune response if it is activated in the liver.

TLR3 recognizes double-stranded RNA (dsRNA), messenger RNA (mRNA), and the synthetic ligand polyinosinic: polycytidylic acid [poly(IC)] [8,9] and TLR3 is unique among TLRs in the fact that it does not signal through MyD88, but rather, it uses a distinct adaptor protein, TRIF (TIR domaincontaining adaptor-inducing IFN- $\beta$ ). TLR3 signaling may induce two downstream pathways, the inflammatory or the apoptotic pathway. The inflammatory pathway is mediated mainly by Ripl and leads to NF- $\kappa$ B activation. The apoptotic pathway, on the other hand, was shown to be mediated by Rip3 and results in caspase- 8 activation [10, 11]. It has been evidenced that the TLR3 detects intracellular viral dsRNA and subsequently activates NF- $\kappa$ B via the TRIF pathway [12]. Previous studies reported that TLR3-induced IFN response was enhanced in hepatocytes isolated from patients with $\mathrm{HCV}$ infection. This hyperresponsiveness could be mimicked in native PHHs consistently stimulated with low dose of poly I:C. The data suggested that durable activation of TLR3 
by low doses of viral replicative intermediates increases the sensitivity to viral invasion [13]. These findings shed new light on the relevance of TLR3 in the pathogenesis of HBV-infected HCC. In this regard, exogenous activation of TLR3 represents an attractive therapeutic strategy to combat chronic viral pathogens such as HBV and HCV.

In the present study, we detected the expression of TLR3 in human HBV-associated HCC tissues and its relation to HBV infection. Furthermore, we stimulated HepG2.2.15 cells by dsRNA to determine the relative contributions of TLR3 to $\mathrm{HBV}$ replication and the possible antiviral mechanism of activating TLR3 in HBV-associated HCC.

\section{Materials and Methods}

2.1. Patient Material. The study group included 68 males and 12 females who were enrolled from the Third People's Hospital of Nantong and Haimen People's Hospital between January 2011 and December 2013, ranging in age from 34 to 76 years, with a mean age of 51.5 years. The patients were selected according to the following criteria: (a) having primary HCC and (b) being previously untreated and with surgery as the first treatment. Therefore, analysis of the data in this series would reflect actual impact of the tumor biology on the clinical outcome. All patients were diagnosed and histopathologically confirmed with HCC and had complete clinical and pathological records including medical records, chest roentgenograms, whole body computed tomography films, and bone and brain scanning data. The surgery records were reviewed and the confirmed pathological diagnosis, tumor size, related hepatitis/liver cirrhosis, metastasis, and serum alpha fetoprotein (AFP) values, and other relevant data were analyzed. Negative controls were established from matched adjacent nontumor liver tissues (ANT) which were cut from the area $2-5 \mathrm{~cm}$ away from HCC nodules. They were derived from 80 cases of HCC. The study was approved by the Ethics Committee of Third People's Hospital of Nantong and Haimen People's Hospital, and all the patients signed informed consent.

2.2. Tissue Microarrays. Tissue microarrays (TMA) were constructed according to the method of E. Qun (Patent number ZL 200810022 170.4). Briefly, all HCC tissues were stained by $\mathrm{H} \& \mathrm{E}$ and reviewed by two histopathologists. Representative areas free from necrotic and hemorrhagic materials were marked in paraffin blocks. Two cylindrical tissue cores (1.6 mm diameter) were removed from the donor blocks and transferred to the recipient paraffin blocks, and their planar array positions were noted. Three different TMA blocks were constructed. Each contained over 100 cylinders and the final TMAs consisted of 80 cases of HCC and 80 cases of ANT. Consecutive sections ( $4 \mu \mathrm{m}$ thick) were cut from the array blocks and placed on adhesion microscope slides for immunohistochemical staining.

2.3. Immunohistochemistry Staining. The Envision+/DAB analysis method was performed on formalin-fixed, paraffinembedded $4 \mu \mathrm{m}$ sections from all patients for the detection of TLR3, HBsAg, and HBcAg in cancer cells. Ten consecutive TMA sections were prepared from TMA block and stained. The paraffin slides were dewaxed in xylene. For antigen retrieval, slides were heated at $95^{\circ} \mathrm{C}$ for $10 \mathrm{~min}$ in sodium citrate buffer $(10 \mathrm{mM}$ sodium citrate monohydrate, $\mathrm{pH}$ 6.0) in microwave. The slides were allowed to cool for $20 \mathrm{~min}$ at room temperature and then incubated in Envision + peroxidase blocking solution (Dakocytomation, Glostrup, Denmark) for $5 \mathrm{~min}$ and rinsed with $0.05 \%$ Trisbuffered saline (TBS)/Tween 20 buffer, pH 7.4. The slides were then incubated with primary antibodies for $30 \mathrm{~min}$ at room temperature. Rabbit anti-TLR3 monoclonal antibodies (diluted 1:100) were obtained from Abcam. Rabbit monoclonal antibodies against human $\mathrm{HBsAg}$ and $\mathrm{HBcAg}$ (diluted $1: 100$ ) and mouse monoclonal antibodies CD3, CD68, CD56, and CD117 (diluted 1:100) were all purchased from Fuzhou Maixin Biotech. Co., Ltd., China. The slides were washed with 0.05\% Tween 20 in TBS ( $\mathrm{pH}$ 7.4). Detection was achieved with the DAKO Envision+/HRP system (DAKO, Carpinteria, CA, USA). The color was developed by a $15 \mathrm{~min}$ incubation with a diaminobenzidine (DAB) solution (DAB kit IL1-9032) (Fuzhou Maixin Biotech. Co., Ltd., China), and sections were slightly counterstained with hematoxylin. Positive controls and negative controls (TBS was substituted for primary antibody at the same concentration) were performed for each immunohistochemical run.

TLR3 located on cytomembrane and cytoplasm of HCC cells. HBsAg and and HBcAg located on cytoplasm and nucleus of HCC cells. CD3, CD68, CD56, and CD117 located on cytoplasm of interstitial immunoreactive cells, each separately representing $\mathrm{T}$ cells, Kupffer cells, NK cells, and mast cells.

\subsection{Terminal Deoxynucleotidyl Transferase-Mediated dUTP} Nick End Labeling (TUNEL) Staining. TUNEL detection kit (Promega, USA) was employed for the detection of neuronal apoptosis. In brief, paraffin-embedded sections were deparaffinized and dehydrated. After washing in phosphate-buffered saline (PBS), sections were treated with $20 \mu \mathrm{g} / \mathrm{mL}$ proteinase $\mathrm{K}$ for $20 \mathrm{~min}$. After washing in PBS thrice ( $3 \mathrm{~min}$ for each), sections were rinsed with $0.3 \%$ Triton X-100 for $10 \mathrm{~min}$ followed by washing in PBS. These sections were incubated with TUNEL reaction mixture at $37^{\circ} \mathrm{C}$ for $1 \mathrm{~h}$. Following washing in PBS thrice ( $3 \mathrm{~min}$ for each), sections were treated with HRP conjugated streptavidin (1:200, Beijing Zhongshan Biotech. Co., Ltd.) at $37^{\circ} \mathrm{C}$ for $30 \mathrm{~min}$. After washing in PBS thrice ( $3 \mathrm{~min}$ for each), sections were treated with $0.04 \%$ $\mathrm{DAB}$ and $0.03 \% \mathrm{H}_{2} \mathrm{O}_{2}$ at room temperature for visualization for $8-12 \mathrm{~min}$. After washing in water, counterstaining was done with hematoxylin followed by mounting with resin. In the negative control, TUNEL reaction mixture was replaced with PBS. The positive control sections were pretreated with DNase I for $10 \mathrm{~min}$ followed by TUNEL staining. Cells with blue granules in the nucleus were regarded as positive for TUNEL. We counted the TUNEL-positive cells in the RGC layer of each sample in $10 \mathrm{HPF}$ (400x). Positivity was graded according to the percentage of tumor cells stained as negative (0-5\%), weak (6-30\%), and strong (30-100\%). 
TABLE 1: The primers used in the experiments.

\begin{tabular}{lcl}
\hline Number & Name & Sequence $\left(5^{\prime} \rightarrow 3^{\prime}\right)$ \\
\hline \multirow{2}{*}{ Hs-HBsAg } & F & TGGTTATCGCTGGATGTGTCTG \\
& R & CCGTGCTGGTGGTTGAGG \\
\hline \multirow{2}{*}{ Hs-HBcAg } & F & TGTGGTTATCCTGCGTTAATG \\
& R & GCGTCAGCAAACACTTGG \\
\hline \multirow{2}{*}{ Hs-TLR3 } & F & TCCCAGCCTTACAGAGAAGC \\
& R & CCTGTGAGTTCTTGCCCAAT \\
\hline \multirow{2}{*}{ Hs-GAPDH } & F & GAAGGTGAAGGTCGGAGTC \\
& R & GAAGATGGTGATGGGATTC \\
\hline
\end{tabular}

2.5. dsRNA Synthesized. dsRNA was designed based on cell surface TLR3 sensitive viral sequences in human echovirus, human poliovirus, enterovirus 70, and coxsackievirus from GenBank. Furthermore, the viral sequences were submitted for basic local alignment search tool (BLAST) analysis (http://www.ncbi.nlm.nih.gov/blast/) to ensure that the sequence was not homologous to human genes. The target sequence of dsRNA was CCGGCCCCUGAAUGCGGCUAAUC (23 nt) [14] and was synthesized by Biomics Biotechnologies Co., Ltd., Jiangsu, China.

2.6. Cell Culture. The human HCC cell line HepG2.2.15 with secreting HBV was purchased from Ruijin Hospital (Shanghai, China). Cells were maintained in Dulbecco's modified Eagle's medium (DMEM) (Gibco BRL, Grand Island, NY, USA) supplemented with $20 \%$ fetal bovine serum (FBS), $2 \mathrm{mM}$ L-glutamine, and $100 \mathrm{U} / \mathrm{mL}$ penicillin-streptomycin mixture (Gibco BRL) at $37^{\circ} \mathrm{C}$ and $5 \% \mathrm{CO}_{2}$ in a humidified chamber.

2.7. $q R T-P C R$. HepG2.2.15 cells were seeded into the wells of a 6-well culture plate and allowed to grow until $80 \%$ confluence. Subsequently, these cells were treated with the dsRNA $(10 \mu \mathrm{g} / \mathrm{mL})$ and PBS (negative control), respectively. After treatment at $37^{\circ} \mathrm{C}$ for 24 hours, total RNA was isolated from HepG2.2.15 cells using TRIzol (Invitrogen, Carlsbad, CA). qRT-PCR was performed for TLR3, HBsAg, and $\mathrm{HBcAg}$ using an ABI 7700 Sequence Detection System (Applied Biosystems). Cycling conditions for amplification were $95^{\circ} \mathrm{C}$ for $3 \mathrm{~min} ; 35$ cycles at $95^{\circ} \mathrm{C}$ for $45 \mathrm{sec}, 60^{\circ} \mathrm{C}$ for $45 \mathrm{sec}$, and $72^{\circ} \mathrm{C}$ for $30 \mathrm{sec}$; and, finally, $72^{\circ} \mathrm{C}$ for $7 \mathrm{~min}$. The primers are listed in Table 1. Each human gene expression was normalized to GAPDH mRNA copies from the same sample.

2.8. Western Blot. HepG2.2.15 cells were treated as described by qRT-PCR analysis. Immunoprecipitation cell lysis buffer was added to the wells, and the plate was put on ice for 30 minutes; then cells treated as described above were scraped, and cell lysate was removed to $1.5 \mathrm{~mL}$ EP tubes and spun for 15 minutes. The supernatant was taken for the experiment. Protein concentrations were determined by an optical density (Eppendor, Hamburg, Germany). Proteins were separated by $10 \%$ polyacrylamide gel electrophoresis and then transferred onto polyvinylidene fluoride (PVDF) membranes (Millipore, USA) at $350 \mathrm{~mA}$ for $2 \mathrm{~h}$, which was later soaked for $2 \mathrm{~h}$ on
TABLE 2: TLR3 expression in HCC and ANT tissues.

\begin{tabular}{lcccccccc}
\hline \multirow{2}{*}{ Sample } & $N$ & \multicolumn{2}{c}{ Positive $n$} & \multirow{5}{c}{ Expressing pattern* } & \multirow{2}{*}{$P$} \\
& & + & $\%$ & & $\mathrm{M}$ & $\mathrm{P}$ & $\mathrm{M} / \mathrm{P}$ & \\
\hline HCC & 80 & 47 & 58.75 & & 8 & 25 & 14 & $>0.05$ \\
ANT & 80 & 55 & 68.75 & & 2 & 36 & 17 & \\
\hline
\end{tabular}

${ }^{*} \mathrm{P}, \mathrm{M}$, and $\mathrm{M} / \mathrm{P}$, respectively, represent the expressing pattern of cytoplasm, cytomembrane, and cytoplasm/cytomembrane.

a blocking solution (Tris-buffered saline containing 5\% nonfat dry milk and $0.01 \% \mathrm{vol} / \mathrm{vol}$ Tween 20). Membranes were incubated for $18 \mathrm{~h}$ at $4^{\circ} \mathrm{C}$ with anti-TLR3 monoclonal antibodies (diluted 1:1000, Abcam) and anti-human HBsAg and HBcAg (diluted 1:500) antibodies (Fuzhou Maixin Biotech. Co., Ltd., China). Anti- $\beta$-actin mouse monoclonal antibody (Sigma, USA) was used as internal control. After incubation, the membrane was washed 3 times, and peroxidaseconjugated secondary antibodies (ICN Laboratories, Irvine, CA; diluted 1:10,000) were added and incubated for an additional one hour. Reaction was visualized by the ECL chemiluminescence detection system (Pierce, USA) on radiographic films (Koda, USA) on BIO-RAD ChemiDoc XRS (Bio-Rad, USA). The results were analyzed using ImageJ software.

2.9. Flow Cytometry Assay. Flow cytometry (Beckman Coulter, Fullerton, CA, USA) was used to determine the apoptotic rate. The HepG2.2.15 cells treated with dsRNA or PBS were suspended in a $500 \mu \mathrm{L}$ binding buffer (Becton Dickinson, USA), incubated with $5 \mu \mathrm{L}$ Annexin V-FITC/PI (Becton Dickinson, USA) and $5 \mu \mathrm{L}$ propidium iodide (PI) (Becton Dickinson, USA) for 15 minutes. Phosphatidyl serine translocation to the cell surface serves as an indicator of early apoptotic cells; therefore, Annexin V-positive and PInegative cells were identified as apoptotic cells. The apoptotic rate was determined using Cell Quest software (FCM, Becton Dickinson).

2.10. Statistical Analysis. Statistical analysis was performed using SPSS 17.0 for Windows. Differences between groups were evaluated with $\chi^{2}$, Fisher exact test, and Spearman rank correlation analysis. A $P$ value $<0.05$ was considered significant.

\section{Results}

3.1. TLR3 Expression and Location in HCC and ANT Tissues. The expressions of TLR3 in HCC and ANT were examined by immunohistochemical analysis, which were showed in cytoplasm, cytomembrane, or cytoplasm/cytomembrane. No significant difference was observed in positive rate and expression pattern of TLR3 between HCC and ANT samples $\left(\chi^{2}=1.7309, P=0.189, \chi^{2}=5.512\right.$, and $\left.P=0.064\right)$ (Figure 1 and Table 2).

3.2. Association of TLR3 Expression with Clinicopathologic Features of HCC. In this paper, the ratio of HCC tissues with HBsAg and HBcAg infection was 27.5\% (22/80) and $15 \%(12 / 80)$, respectively (Figure 2$)$. The correlation of TLR3 

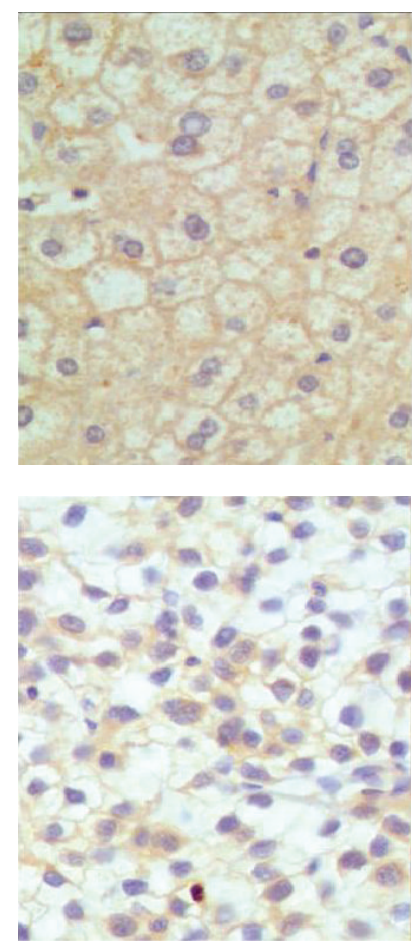

(a)
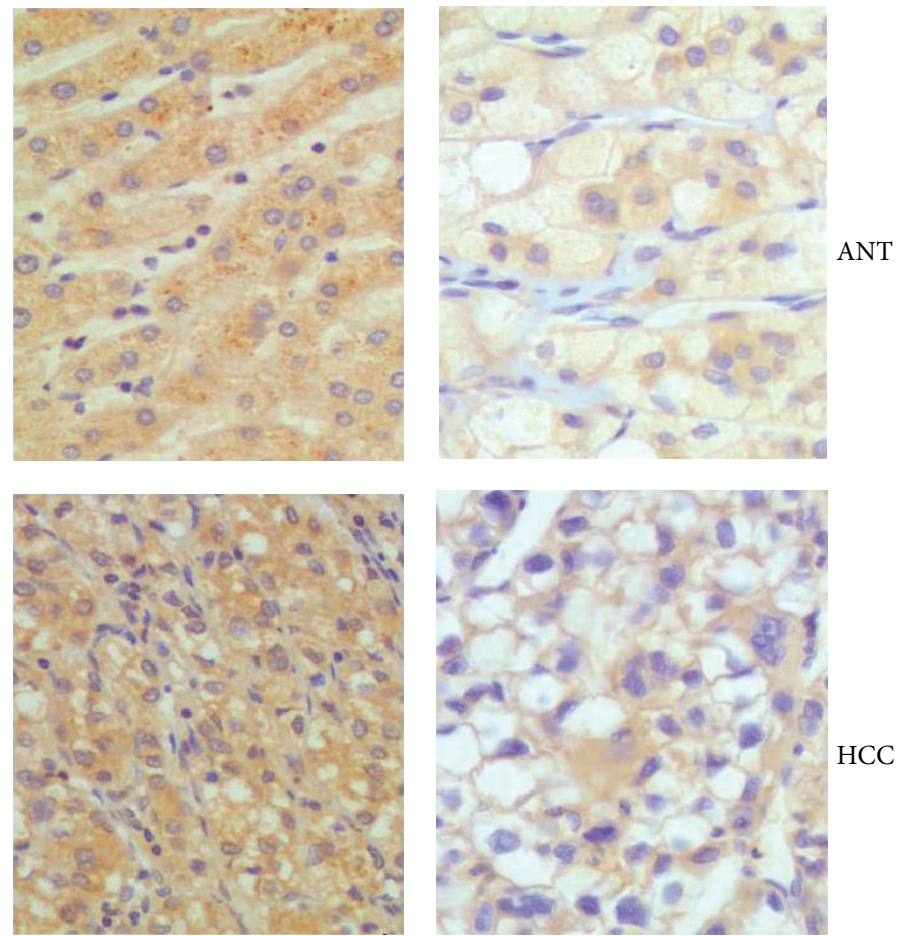

(b)

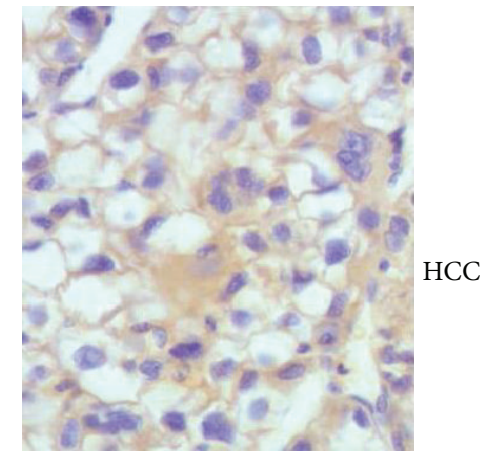

(c)

FIgURE 1: TLR3 expression and location in HCC and ANT tissues. TLR3 exhibited cytoplasm (a), cytomembrane staining (b), and cytoplasm/cytomembrane (c), respectively, in HCC and ANT. (IHC magnification $\times 200$ ).

expression with the clinicopathologic characteristics of HCC was investigated (Table 3 ). Intratumoral TLR3 positive rate was negatively related to the serum AFP levels $\left(\chi^{2}=6.2411\right.$, $P=0.012)$ and positively related to HBsAg infection $\left(\chi^{2}=\right.$ 9.5477, $P=0.002$ ) and tumor with cirrhosis background $\left(\chi^{2}=26.5278, P=0.000\right)$. And yet TLR3 expressing pattern was related to HBsAg infection $\left(\chi^{2}=12.999, P=0.002\right)$. However there were no correlations between TLR3 positive rate and age, gender, $\mathrm{HCC}$ size, grates, and $\mathrm{HBcAg}$ infection $(P>0.05)$.

3.3. Association of TLR3 Expression with Interstitial Immunoreactive Cells. Interstitial immunoreactive cells, T cells, Kupffer cells, NK cells, and mast cells were, respectively, marked CD3, CD68, CD56, and CD117 antibodies by immunohistochemical staining (Figure 3). TLR3 expression was positively correlated with interstitial infiltration of T cell $\left(\chi^{2}=10.944\right.$, $P=0.001<0.05 ; r=0.370, P=0.001<0.05)$, Kupffer cells $\left(\chi^{2}=7.230, P=0.007<0.05 ; r=0.301, P=0.007<0.05\right)$, and NK cells $\left(\chi^{2}=5.792, P=0.014<0.05 ; r=0.269\right.$, $P=0.016<0.05)$. TLR3 membrane expression related to interstitial infiltration of T cells $\left(\chi^{2}=6.084, P=0.017<\right.$ $0.05 ; r=0.276, P=0.013<0.05)$ and NK cells $\left(\chi^{2}=3.855\right.$, $P=0.071>0.05 ; r=0.220, P=0.050)$ and TLR3 cytoplasm expression related to Kupffer cells infiltration $\left(\chi^{2}=8.727\right.$, $P=0.003<0.05 ; r=0.330, P=0.003<0.05)$. But TLR3 positive rate and expressing patterns have no correlation with mast cells $(P>0.05)$ (Table 4$)$.
3.4. Association of TLR3 Expression with Tumor Apoptosis in HCC. The results of TUNEL detection showed that the apoptosis index in HCC tissues was 55\% (44/80) (Figure 4). The expression of TLR3 positively correlated with HCC apoptosis $\left(\chi^{2}=11.2517, P<0.001 ; r=0.3354, P<\right.$ $0.001)$. No significant difference was observed between HCC apoptosis and TLR3 expression patterns in HCC $(P>0.05)$ (Table 5).

3.5. Stimulation of TLR3 Inhibits HBV Secretion of HepG2.2.15 Cells. TLR3 is generally believed to play an important role in the innate immune response against viral infection, including viral hepatitis infection, although controversial results have been reported [15]. The controversial reports on the role of TLR3 in the antiviral defense may be due to the difference in the type of viruses, the type of cells that are infected, the viral load, its model of infection (endoplasmic versus cytoplasmic), and stage of infection. We tested the expression of HBsAg and HBcAg of HepG2.2.15 cells by using qRT-PCR and western blot analysis after treatment with dsRNA. The results showed that when the cells were treated with dsRNA, the levels of $\mathrm{HBsAg}$ and $\mathrm{HBcAg}$ were greatly reduced (Figures 5(a) and 5(b)). These results showed that HBsAg and $\mathrm{HBcAg}$ protein were less expressed in dsRNA treated HepG2.2.15 cells.

3.6. dsRNA Inducing Cell Apoptosis of HepG2.2.15 Cells. Inhibition of cell growth could result from the induction of apoptosis, cell growth arrest, and/or the inhibition of 


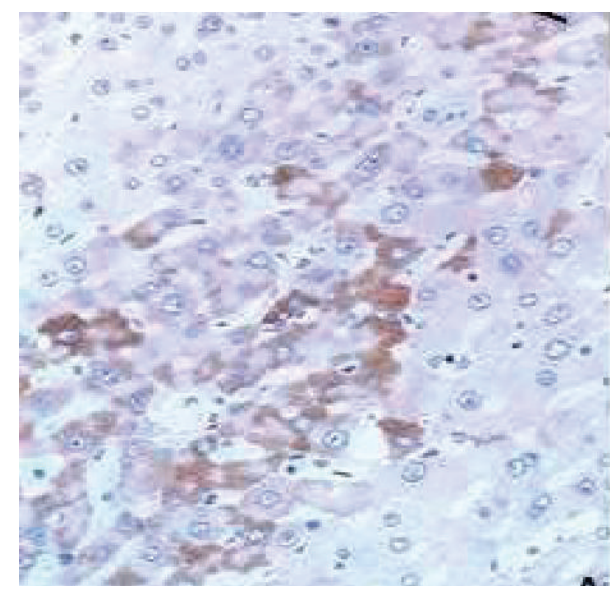

(a)

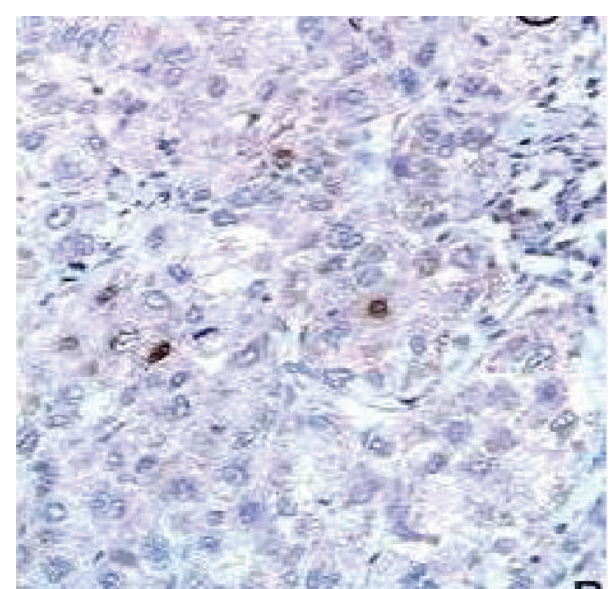

(b)

Figure 2: HBsAg and HBcAg expression in HCC tissues. (a) HBsAg expression in the cytoplasm; (b) HBcAg expression in the cell nucleus. IHC stain, magnification $\times 200$.

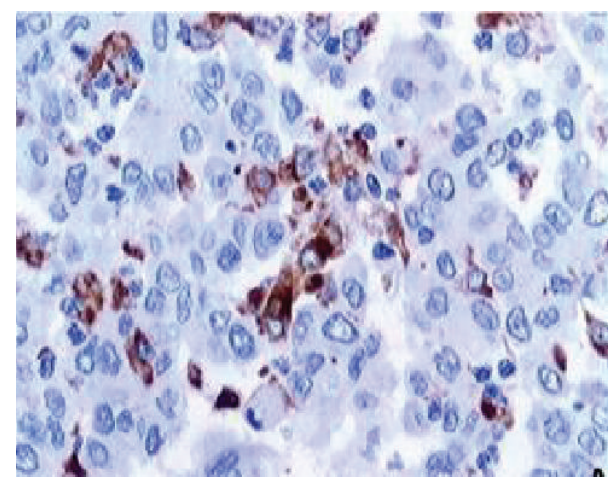

(a)

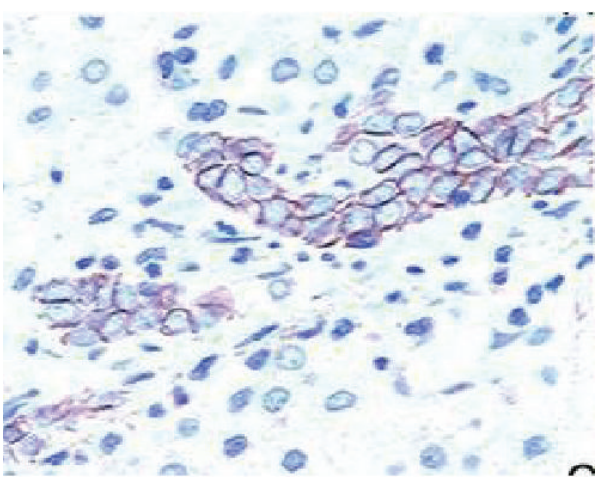

(c)

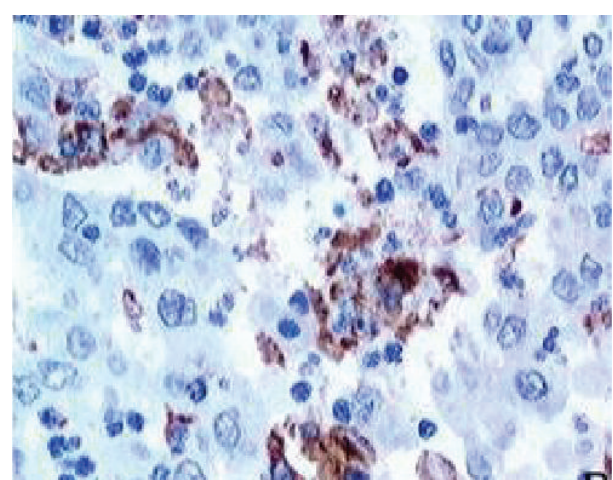

(b)

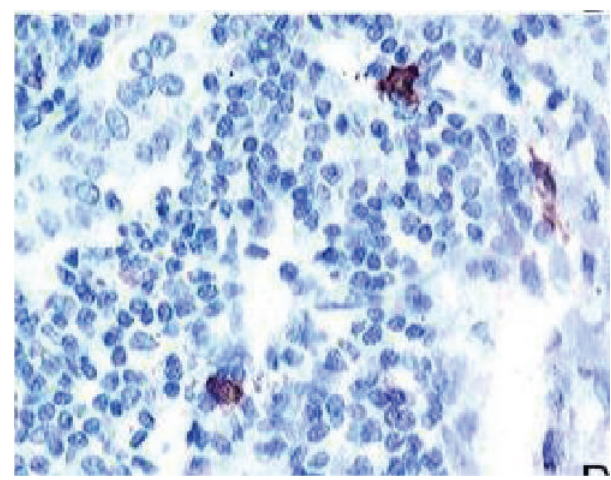

(d)

FIGURE 3: Interstitial immunoreactive cells infiltration, T cells (a), Kupffer cells (b), NK cells (c), and mast cells (d) were, respectively, marked CD3, CD68, CD56, and CD117 antibodies by immunohistochemical staining in HCC (IHC $\times 400)$.

growth. We investigated whether activation of the expression of TLR3 induced apoptosis in HepG2.215 cells. The Annexin V-FITC/PI double staining was used as indicator of apoptosis. Activation of TLR3 increased the percentage of Annexin V-positive/PI-negative cells (Figure 6). We found that cells treated with dsRNA for $24 \mathrm{~h}$ resulted in decreased cell viability and increased cell apoptosis.

\section{Discussion}

$\mathrm{HBV}$ as the main prevalent infectious agent plays important roles in inducing severe liver diseases. Previous studies demonstrated that, during prolonged forms of $\mathrm{HBV}$ infection including chronic, asymptomatic, and occult forms, patients are unable to eradicate $\mathrm{HBV}$ from hepatocytes completely 
TABLE 3: Correlation between TLR3 expression and clinicopathologic characteristics in HCC.

\begin{tabular}{|c|c|c|c|c|c|c|c|c|}
\hline \multirow{2}{*}{ Item } & \multirow{2}{*}{$N$} & \multicolumn{2}{|c|}{ Positive rate } & \multirow{2}{*}{$P$} & \multicolumn{3}{|c|}{ Expressing pattern } & \multirow{2}{*}{$P$} \\
\hline & & + & $\%$ & & M & $\mathrm{P}$ & $\mathrm{M} / \mathrm{P}$ & \\
\hline \multicolumn{9}{|l|}{ Age (year) } \\
\hline$\leq 51.5$ & 38 & 21 & 55.26 & \multirow{2}{*}{$>0.05$} & 4 & 10 & 7 & \multirow{2}{*}{$>0.05$} \\
\hline$>51.5$ & 42 & 26 & 61.90 & & 4 & 15 & 7 & \\
\hline \multicolumn{9}{|l|}{ Sex } \\
\hline Male & 68 & 38 & 55.88 & \multirow{2}{*}{$>0.05$} & 6 & 20 & 12 & \multirow{2}{*}{$>0.05$} \\
\hline Female & 12 & 9 & 75.00 & & 2 & 5 & 2 & \\
\hline \multicolumn{9}{|c|}{$\operatorname{AFP}(n g / m L)$} \\
\hline$<400$ & 64 & 42 & 65.63 & \multirow{2}{*}{$<0.05$} & 6 & 22 & 14 & \multirow{2}{*}{$>0.05$} \\
\hline$\geq 400$ & 16 & 5 & 31.25 & & 2 & 3 & 0 & \\
\hline \multicolumn{9}{|c|}{ Tumor size } \\
\hline$<2 \mathrm{~cm}$ & 6 & 4 & 66.67 & \multirow{3}{*}{$>0.05$} & 1 & 2 & 1 & \multirow{3}{*}{$>0.05$} \\
\hline $2-5 \mathrm{~cm}$ & 49 & 25 & 51.02 & & 6 & 14 & 5 & \\
\hline$>5 \mathrm{~cm}$ & 25 & 18 & 72.00 & & 1 & 9 & 8 & \\
\hline \multicolumn{9}{|l|}{ Grade } \\
\hline G1 & 8 & 6 & 75.00 & \multirow{3}{*}{$>0.05$} & 0 & 6 & 0 & \multirow{3}{*}{$>0.05$} \\
\hline G2 & 33 & 21 & 63.64 & & 4 & 10 & 7 & \\
\hline G3 & 39 & 20 & 51.28 & & & & & \\
\hline \multicolumn{9}{|l|}{ HBsAg } \\
\hline+ & 22 & 19 & 86.36 & \multirow{2}{*}{$<0.05$} & 2 & 16 & 1 & \multirow{2}{*}{$<0.05$} \\
\hline- & 58 & 28 & 48.28 & & 6 & 9 & 13 & \\
\hline \multicolumn{9}{|l|}{$\mathrm{HBcAg}$} \\
\hline+ & 12 & 7 & 58.33 & \multirow{2}{*}{$>0.05$} & 1 & 3 & 3 & \multirow{2}{*}{$>0.05$} \\
\hline- & 68 & 40 & 58.82 & & 7 & 22 & 11 & \\
\hline \multicolumn{9}{|l|}{ Cirrhosis } \\
\hline+ & 42 & 36 & 85.71 & \multirow{2}{*}{$<0.05$} & 5 & 20 & 11 & \multirow{2}{*}{$>0.05$} \\
\hline- & 38 & 11 & 28.95 & & 3 & 5 & 3 & \\
\hline
\end{tabular}

TABLE 4: Association of TLR3 expression with interstitial immunoreactive cells.

\begin{tabular}{|c|c|c|c|c|c|c|c|c|}
\hline \multirow{2}{*}{ TUNEL } & \multirow{2}{*}{$N$} & \multicolumn{2}{|c|}{ TLR3 } & \multirow{2}{*}{$P$} & \multicolumn{3}{|c|}{ Expressing pattern } & \multirow{2}{*}{$P$} \\
\hline & & + & $\%$ & & M & $\mathrm{P}$ & $\mathrm{M} / \mathrm{P}$ & \\
\hline \multicolumn{9}{|l|}{ CD3 } \\
\hline$\geq 50 / \mathrm{HPF}$ & 37 & 29 & 78.38 & \multirow{2}{*}{$<0.05$} & 7 & 13 & 9 & \multirow{2}{*}{$<0.05$} \\
\hline$<50 / \mathrm{HPF}$ & 43 & 18 & 41.86 & & 1 & 12 & 5 & \\
\hline \multicolumn{9}{|l|}{ CD68 } \\
\hline$\geq 5 / \mathrm{HPF}$ & 48 & 34 & 70.83 & \multirow{2}{*}{$<0.05$} & 5 & 21 & 8 & \multirow{2}{*}{$<0.05$} \\
\hline$<5 / \mathrm{HPF}$ & 32 & 13 & 40.63 & & 3 & 4 & 6 & \\
\hline \multicolumn{9}{|l|}{ CD56 } \\
\hline$\geq 5 / \mathrm{HPF}$ & 18 & 15 & 83.33 & \multirow{2}{*}{$<0.05$} & 4 & 7 & 4 & \multirow{2}{*}{$<0.05$} \\
\hline$<5 / \mathrm{HPF}$ & 62 & 32 & 51.61 & & 4 & 18 & 10 & \\
\hline \multicolumn{9}{|l|}{ CD117 } \\
\hline$\geq 10 / \mathrm{HPF}$ & 25 & 15 & 60.00 & \multirow{2}{*}{$>0.05$} & 2 & 7 & 6 & \multirow{2}{*}{$>0.05$} \\
\hline$<10 / \mathrm{HPF}$ & 55 & 32 & 58.18 & & 6 & 18 & 8 & \\
\hline
\end{tabular}

[16]. Several lines of evidences suggested that a synergistic interaction between environmental carcinogens and HBVcarcinogens may play a critical role in the carcinogenesis of
TABLE 5: Correlation between TUNEL expression and TLR3 expression in HCC.

\begin{tabular}{|c|c|c|c|c|c|c|c|c|}
\hline \multirow{2}{*}{ TUNEL } & \multirow{2}{*}{$N$} & \multicolumn{2}{|c|}{ TLR3 } & \multirow{2}{*}{$P$} & \multicolumn{3}{|c|}{ Expressing pattern } & \multirow{2}{*}{$P$} \\
\hline & & - & + & & M & $\mathrm{P}$ & $\mathrm{M} / \mathrm{P}$ & \\
\hline- & 36 & 27 & 9 & \multirow{2}{*}{$<0.05$} & 2 & 4 & 3 & \multirow{2}{*}{$>0.05$} \\
\hline+ & 44 & 6 & 38 & & 6 & 21 & 11 & \\
\hline
\end{tabular}

HCC $[17,18]$. The main mechanisms responsible for development of the forms of hepatitis B are yet to be identified.

It has been evidenced that TLRs are essential for the recognition of invading pathogens and serve as an important link between innate and adaptive immunity. TLR3 is an endosomal receptor for dsRNA and is expressed in several subsets of immune cells, including dendritic cells and natural killer (NK) cells. TLR3 is also expressed by fibroblasts [19], lung epithelial cells [20], hepatocytes [21], and several types of tumor cells. TLR3 is involved in antiviral responses and the production of type I interferons (IFNs) [22]. It is the only TLR that signals exclusively through the MyD88-independent pathway, which activates TRIF and IRF3 and results in production of anti-inflammatory mediators such as IFN- $\beta$, IL-10, TGF- $\beta$, and RANTES [23]. Previous studies found that TLR3 is an important modulator of HCC progression and is a potential target for novel immunotherapy [24].

In the present study, we investigated the significance and relationship between TLR3 expression and HBV infection, apoptosis, and interstitial immunoreactive cells infiltration in HCC. We found that TLR3 was generally expressed in HCC tissues (positive rate 58.75\%) and ANT (positive rate 68.75\%), located in the cytoplasm and cytomembrane of HCC cells. These results are similar to those by Yoneda et al. [25]. In this study, expression level of TLR3 was negatively correlated with serum AFP levels. AFP is a protein that can be expressed by HCC cells, with extremely complicated biologic activities. Studies have shown that AFP plays double roles in both inhibiting the immune system and promoting the growth of cancer cells. These results indicate that the expression level of TLR3 was positively correlated with HBsAg infection and HCC with cirrhosis background, the higher levels and cellular HBsAg infection, the higher positive rate of TLR3. The results also indicate that the HCC with HBV infection may upregulate the synthesis of dsRNA which were involved in replication or transcription process and then activate TLR3, which in turn promote interstitial immunoreactive cells and induce inflammatory cytokine production. The above process activate the body's adaptive immune response that will against viruses. This hypothesis had been confirmed by detecting the relationship between TLR3 expression, HBsAg expression, and cirrhosis background. Consequently, high expression of TLR3 is based on high levels of HBV infection. The results suggest the importance of TLR3 in antiviral immunity in vivo. In addition, we also examined the potential antiviral effect of TLR3 in vitro. dsRNA activation of TLR3, which signals through a TRIF-dependent pathway, induces expression of various protective mediators and antiinflammatory cytokines, such as poly I:C, a synthetic dsRNA analog, in human astrocytes [26]. Here, we show that dsRNA 


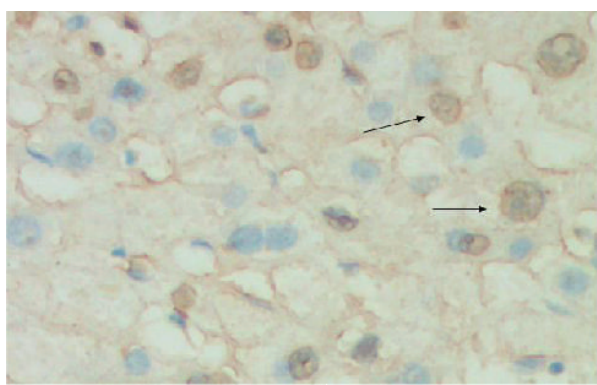

(a)

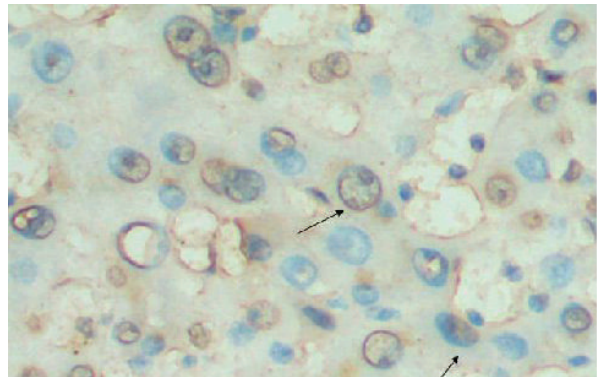

(b)

FIGURE 4: TUNEL detected apoptosis in HCC tissues. Apoptotic nuclei were stained in brownish yellow (indicated by arrow), while normal nuclei were stained in blue (magnification $\times 400$ ).

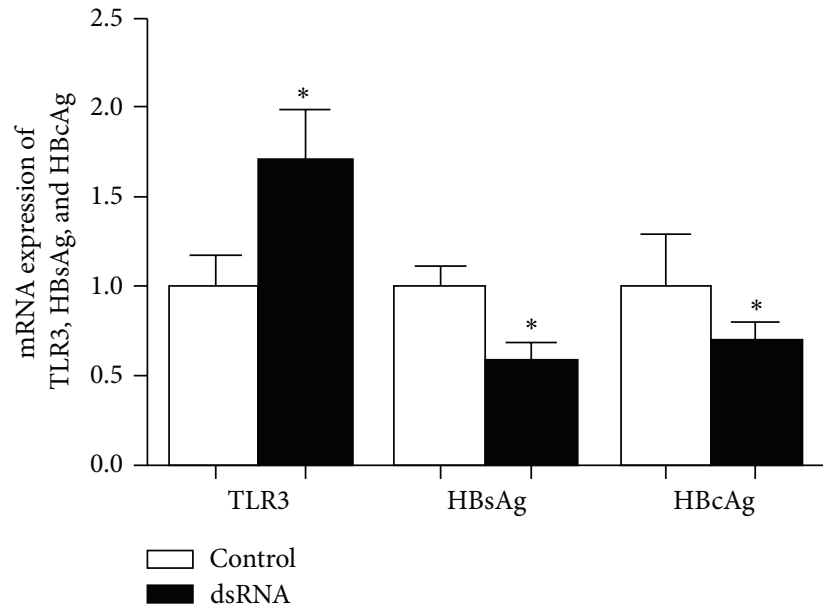

(a)
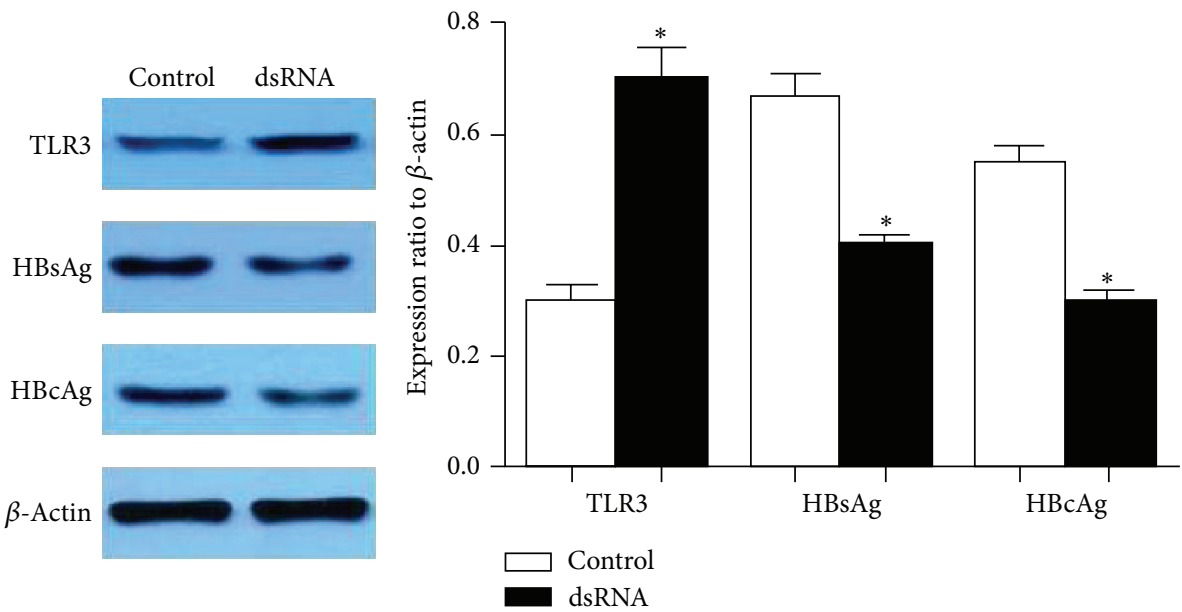

(b)

FIGURE 5: dsRNA stimulated the expression of TLR3 and inhibited the expression of HBsAg and HBcAg in HepG2.2.15 cells. (a) By qRT-PCR. (b) By western blotting $\left({ }^{*} P<0.05\right.$ versus control group).

can inhibit the secretion of HBsAg and HBCAg of HepG2.2.15 cells. Preconditioning with $10 \mu \mathrm{g} / \mathrm{mL}$ dsRNA significantly increased TLR3 expression and decreased $\mathrm{HBsAg}$ and $\mathrm{HBcAg}$ protein expression, which agrees with the experimental results of Mcclary et al. [27]. The antiviral effects of TLR3 signaling on HCC with HBV infection are likely mediated via stimulating of a variety of cells to produce type I IFN that subsequently inhibits HCV or HBV replication [28-31]. These cells include parenchyma cells in HCC and interstitial immunoreactive cells. 

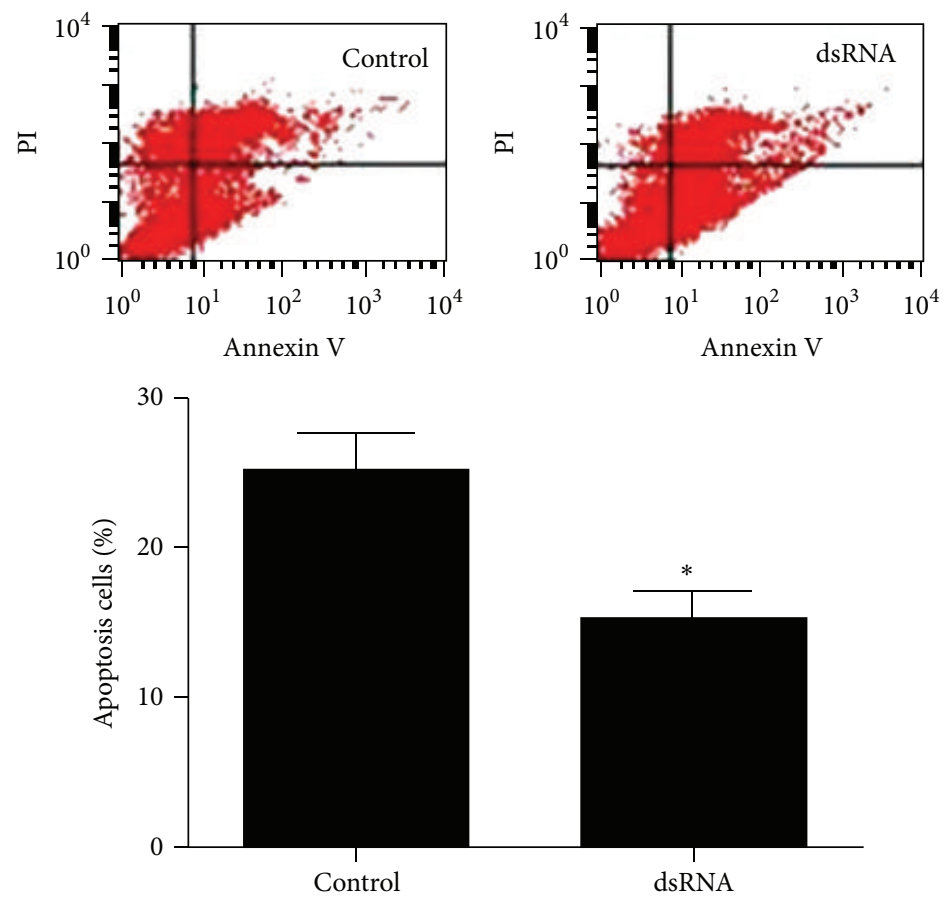

Figure 6: Flow cytometry detection of apoptosis. dsRNA induced HepG2.2.15 cell apoptosis $\left({ }^{*} P<0.05\right.$ versus control group).

Apoptosis is one of the mechanisms leading to cell death when cells have sustained damage to their DNA or cytoskeleton [32]. In this study, we found that the upregulation of TLR3 can not only anti-HBV but also induce apoptosis of HCC cells. We have shown that the expression of TLR3 has positive correlation with apoptosis by TUNEL staining. The results of experiments in vitro were consistent with it. After dsRNA treatment, HepG2.2.15 cell apoptosis was enhanced and activity was decreased. Zorde-Khvalevsky et al. [33] discovered that, during the initial regenerating phase following partial hepatectomy, TLR3 signaling was induced in hepatocytes, leading to activation of NF- $\kappa \mathrm{B}$ and caspase8 and an increase in Rip3 protein levels. Upon activation, caspase- 8 cleaves effector caspases, which leads to cell death by initiating apoptotic program. We reasoned that the TLR3dependent activation of NF- $\kappa \mathrm{B}$ and caspase- 8 in hepatocytes could result in an increase in activated IL- $1 \beta$, subsequently inhibiting hepatocyte proliferation and inducing HepG2.2.15 cell apoptosis. In short, the mechanism by which dsRNA activates TLR3 is very complex and further studies will be conducted.

In conclusion, the upregulation of TLR3 plays a crucial role in the process of $\mathrm{HBV}$ cleaning and inducing $\mathrm{HCC}$ apoptosis in HBV-associated HCC. It suggests that TLR3 activation could represent a powerful and novel therapeutic strategy for the treatment of chronic HBV infection and $\mathrm{HBV}$-associated HCC. However, further studies are required to confirm these findings and to provide better understanding of the TLR3 signaling mechanism in the development of HBV-associated HCC.

\section{Conflict of Interests}

The authors declare that there is no conflict of interests regarding the publication of this paper.

\section{Acknowledgments}

This study was supported by the Foundation of the Production-Study-Research Prospective Joint Research Programs of Jiangsu Province, China (BY 2013042-06), a project funded by the Priority Academic Program Development of Jiangsu Higher Education Institutions, and the Science Foundation of Nantong City, Jiangsu Province, China (no. BK2014001).

\section{References}

[1] Y.-J. Jin, Y.-H. Chung, J. A. Kim et al., "Factors predisposing metastatic tumor antigen 1 overexpression in hepatitis B virus associated hepatocellular carcinoma," Digestive Diseases and Sciences, vol. 57, no. 11, pp. 2917-2923, 2012.

[2] Z. Li, W. Yuan, S. Ning, J. Li, W. Zhai, and S. Zhang, "Role of leptin receptor (LEPR) gene polymorphisms and haplotypes in susceptibility to hepatocellular carcinoma in subjects with chronic hepatitis b virus infection," Molecular Diagnosis and Therapy, vol. 16, no. 6, pp. 383-388, 2012.

[3] M. M. Hassan, L.-Y. Hwang, C. J. Hatten et al., "Risk factors for hepatocellular carcinoma: synergism of alcohol with viral hepatitis and diabetes mellitus," Hepatology, vol. 36, no. 5, pp. 1206-1213, 2002. 
[4] C.-A. Sun, D.-M. Wu, C.-C. Lin et al., "Incidence and cofactors of hepatitis $C$ virus-related hepatocellular carcinoma: a prospective study of 12,008 men in Taiwan," American Journal of Epidemiology, vol. 157, no. 8, pp. 674-682, 2003.

[5] J. M. Llovet, A. Burroughs, and J. Bruix, "Hepatocellular carcinoma," The Lancet, vol. 362, no. 9399, pp. 1907-1917, 2003.

[6] K. Kimura, K. Kakimi, S. Wieland, L. G. Guidotti, and F. V. Chisari, "Activated intrahepatic antigen-presenting cells inhibit hepatitis B virus replication in the liver of transgenic mice," Journal of Immunology, vol. 169, no. 9, pp. 5188-5195, 2002.

[7] K. Kimura, K. Kakimi, S. Wieland, L. G. Guiotti, and F. V. Chisari, "Interleukin-18 inhibits hepatitis B virus replication in the livers of transgenic micet," Journal of Virology, vol. 76, no. 21, pp. 10702-10707, 2002.

[8] L. Alexopoulou, A. C. Holt, R. Medzhitov, and R. A. Flavell, "Recognition of double-stranded RNA and activation of NF- $\kappa \mathrm{B}$ by Toll-like receptor 3," Nature, vol. 413, no. 6857, pp. 732-738, 2001.

[9] K. Karikó, P. Bhuyan, J. Capodici et al., "Exogenous siRNA mediates sequence-independent gene suppression by signaling through toll-like receptor 3," Cells Tissues Organs, vol. 177, no. 3, pp. 132-138, 2004.

[10] W. J. Kaiser and M. K. Offermann, "Apoptosis induced by the toll-like receptor adaptor TRIF is dependent on its receptor interacting protein homotypic interaction motif," Journal of Immunology, vol. 174, no. 8, pp. 4942-4952, 2005.

[11] K.-J. Han, X. Su, L.-G. Xu, L.-H. Bin, J. Zhang, and H.-B. Shu, "Mechanisms of the TRIF-induced interferon-stimulated response element and NF- $\kappa \mathrm{B}$ activation and apoptosis pathways," The Journal of Biological Chemistry, vol. 279, no. 15, pp. 15652-15661, 2004.

[12] M. Karimi-Googheri and M. K. Arababadi, "TLR3 plays significant roles against hepatitis B virus," Molecular Biology Reports, vol. 41, no. 5, pp. 3279-3286, 2014.

[13] R. Broering, M. Lutterbeck, M. Trippler et al., "Long-term stimulation of toll-like receptor 3 in primary human hepatocytes leads to sensitization for antiviral responses induced by poly I: C treatment," Journal of Viral Hepatitis, vol. 21, pp. 480-490, 2014.

[14] Y. Y. Xu, L. Chen, G. L. Wang et al., "A synthetic dsRNA, as a TLR3 pathwaysynergist, combined with sorafenib suppresses HCC in vitro and in vivo," BMC Cancer, vol. 13, article 527, 2013.

[15] M. Schröder and A. G. Bowie, "TLR3 in antiviral immunity: key player or bystander?” Trends in Immunology, vol. 26, no. 9, pp. 462-468, 2005.

[16] M. Karimi-Googheri and M. K. Arababadi, "TLR3 plays significant roles against hepatitis B virus," Molecular Biology Reports, vol. 41, no. 5, pp. 3279-3289, 2014.

[17] S.-Y. Chen, L.-Y. Wang, R. M. Lunn et al., "Polycyclic aromatic hydrocarbon-DNA adducts in liver tissues of hepatocellular carcinoma patients and controls," International Journal of Cancer, vol. 99, no. 1, pp. 14-21, 2002.

[18] H.-C. Wu, Q. Wang, L.-W. Wang et al., "Polycyclic aromatic hydrocarbon- and aflatoxin-albumin adducts, hepatitis B virus infection and hepatocellular carcinoma in Taiwan," Cancer Letters, vol. 252, no. 1, pp. 104-114, 2007.

[19] G. A. Farina, M. R. York, M. Di Marzio et al., "Poly(I:C) drives type i IFN- and TGFB-mediated inflammation and dermal fibrosis simulating altered gene expression in systemic sclerosis," Journal of Investigative Dermatology, vol. 130, no. 11, pp. 2583-2593, 2010.
[20] L. Guillot, R. Le Goffic, S. Bloch et al., "Involvement of Tolllike receptor 3 in the immune response of lung epithelial cells to double-stranded RNA and influenza A virus," The Journal of Biological Chemistry, vol. 280, no. 7, pp. 5571-5580, 2005.

[21] K. Li, Z. Chen, N. Kato, M. Gale Jr., and S. M. Lemon, "Distinct poly(I-C) and virus-activated signaling pathways leading to interferon- $\beta$ production in hepatocytes," The Journal of Biological Chemistry, vol. 280, no. 17, pp. 16739-16747, 2005.

[22] M. Matsumoto, K. Funami, H. Oshiumi, and T. Seya, “Tolllike receptor 3: a link between toll-like receptor, interferon and viruses," Microbiology and Immunology, vol. 48, no. 3, pp. 147$154,2004$.

[23] M. L. Hanke and T. Kielian, "Toll-like receptors in health and disease in the brain: mechanisms and therapeutic potential," Clinical Science, vol. 121, no. 9, pp. 367-387, 2011.

[24] V. Chew, C. Tow, C. Huang et al., "Toll-like receptor 3 expressing tumor parenchyma and infiltrating natural killer cells in hepatocellular carcinoma patients," Journal of the National Cancer Institute, vol. 104, no. 23, pp. 1796-1807, 2012.

[25] K. Yoneda, K. Sugimoto, K. Shiraki et al., "Dual topology of functional Toll-like receptor 3 expression in human hepatocellular carcinoma: Differential signaling mechanisms of TLR3induced NF- $\kappa$ B activation and apoptosis," International Journal of Oncology, vol. 33, no. 5, pp. 929-936, 2008.

[26] M. Bsibsi, C. Persoon-Deen, R. W. H. Verwer, S. Meeuwsen, R. Ravid, and J. M. Van Noort, "Toll-like receptor 3 on adult human astrocytes triggers production of neuroprotective mediators," GLIA, vol. 53, no. 7, pp. 688-695, 2006.

[27] H. Mcclary, R. Koch, F. V. Chisari, and L. G. Guidotti, "Relative sensitivity of hepatitis B virus and other hepatotropic viruses to the antiviral effects of cytokines," Journal of Virology, vol. 74, no. 5, pp. 2255-2264, 2000.

[28] B. Wang, M. Trippler, R. Pei et al., “Toll-like receptor activated human and murine hepatic stellate cells are potent regulators of hepatitis C virus replication," Journal of Hepatology, vol. 51, no. 6, pp. 1037-1045, 2009.

[29] M. Isogawa, M. D. Robek, Y. Furuichi, and F. V. Chisari, "Tolllike receptor signaling inhibits hepatitis B virus replication in vivo," Journal of Virology, vol. 79, no. 11, pp. 7269-7272, 2005.

[30] J. Wu, M. Lu, Z. Meng et al., "Toll-like receptor-mediated control of HBV replication by nonparenchymal liver cells in mice," Hepatology, vol. 46, no. 6, pp. 1769-1778, 2007.

[31] T. Kanda, R. Steele, R. Ray, and R. B. Ray, "Hepatitis C virus infection induces the beta interferon signaling pathway in immortalized human hepatocytes," Journal of Virology, vol. 81, no. 22, pp. 12375-12381, 2007.

[32] J. C. Ferreon, A. C. M. Ferreon, K. Li, and S. M. Lemon, "Molecular determinants of TRIF proteolysis mediated by the hepatitis C virus NS3/4A protease," The Journal of Biological Chemistry, vol. 280, no. 21, pp. 20483-20492, 2005.

[33] E. Zorde-Khvalevsky, R. Abramovitch, H. Barash et al., “Tolllike receptor 3 signaling attenuates liver regeneration," Hepatology, vol. 50, no. 1, pp. 198-206, 2009. 


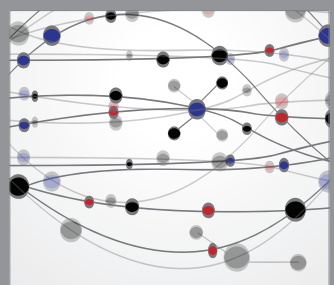

The Scientific World Journal
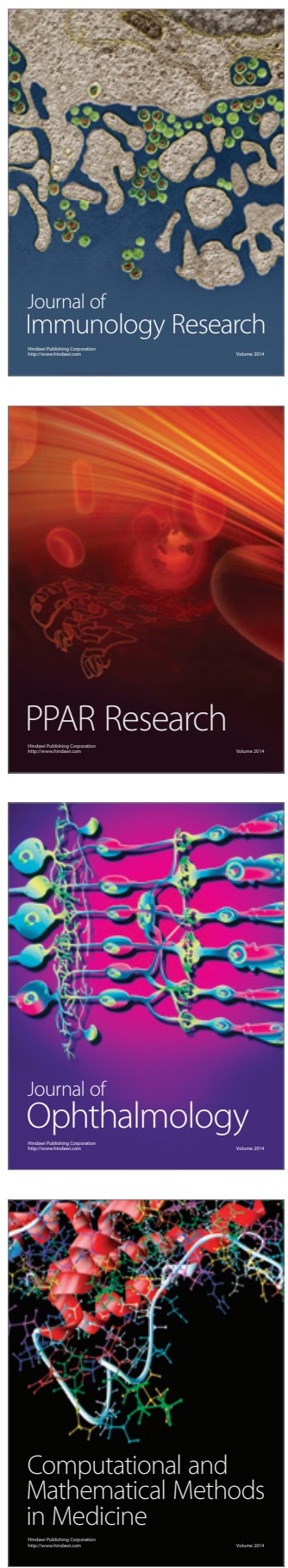

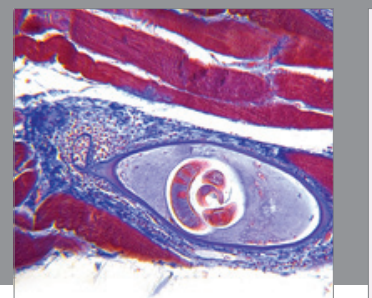

Gastroenterology

Research and Practice
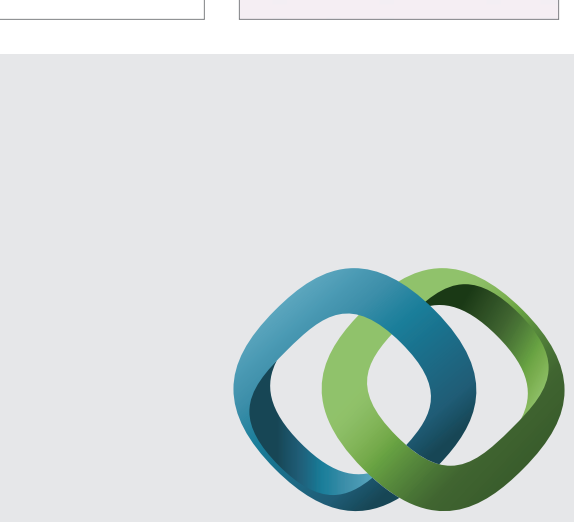

\section{Hindawi}

Submit your manuscripts at

http://www.hindawi.com
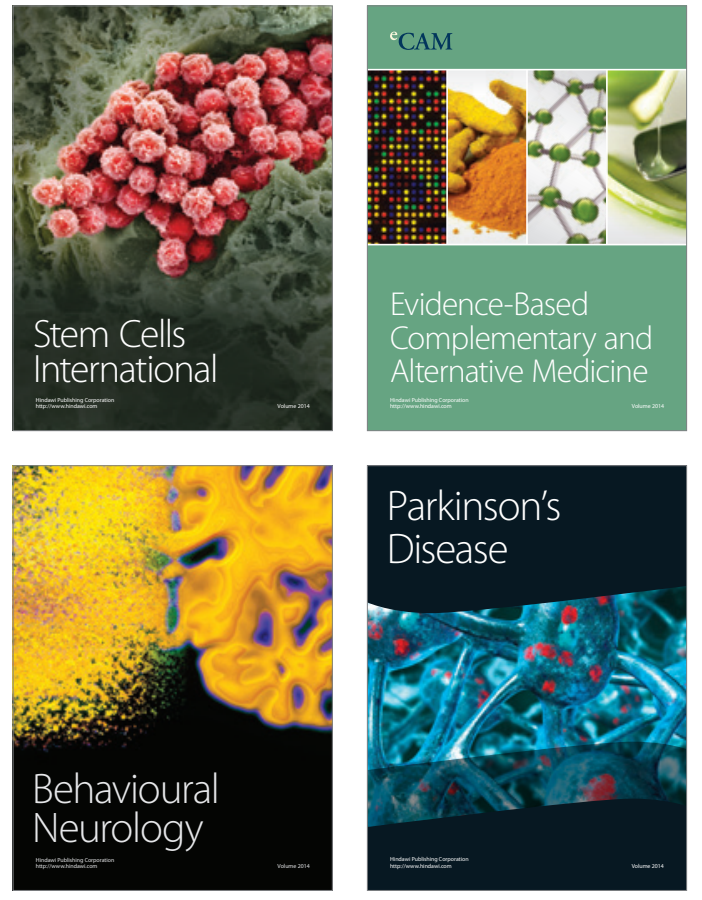
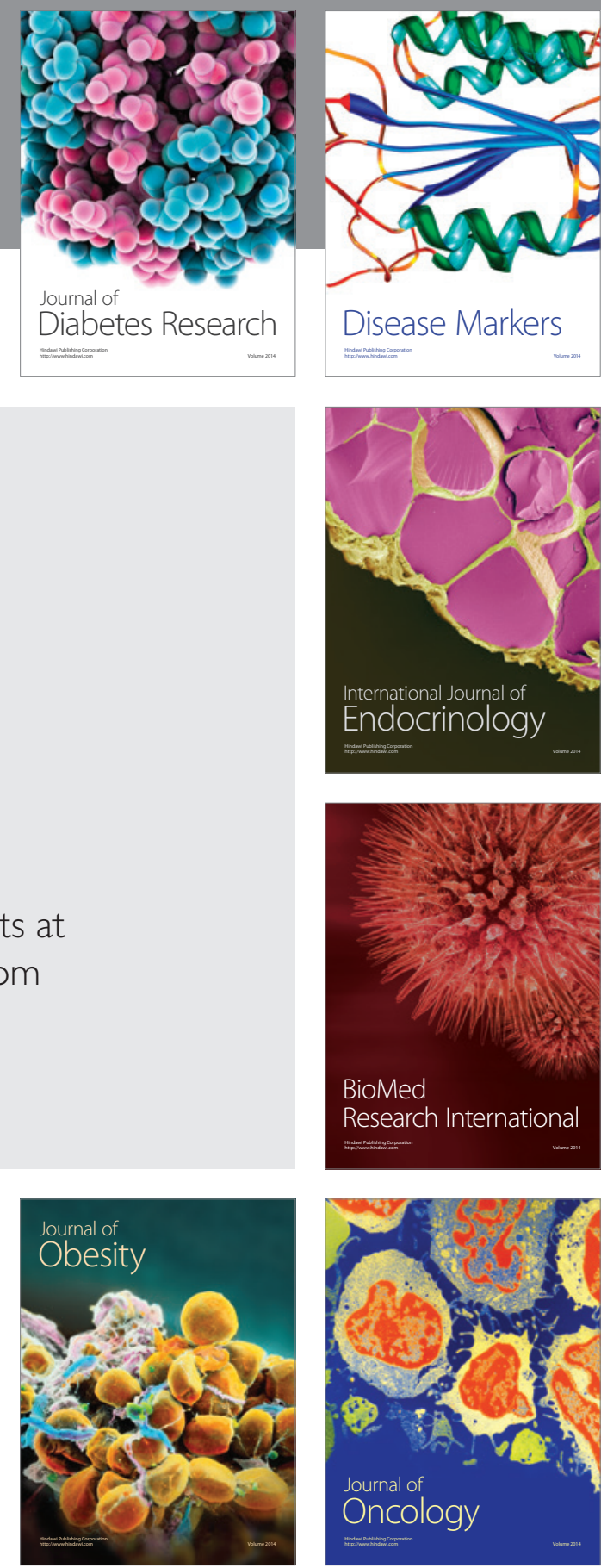

Disease Markers
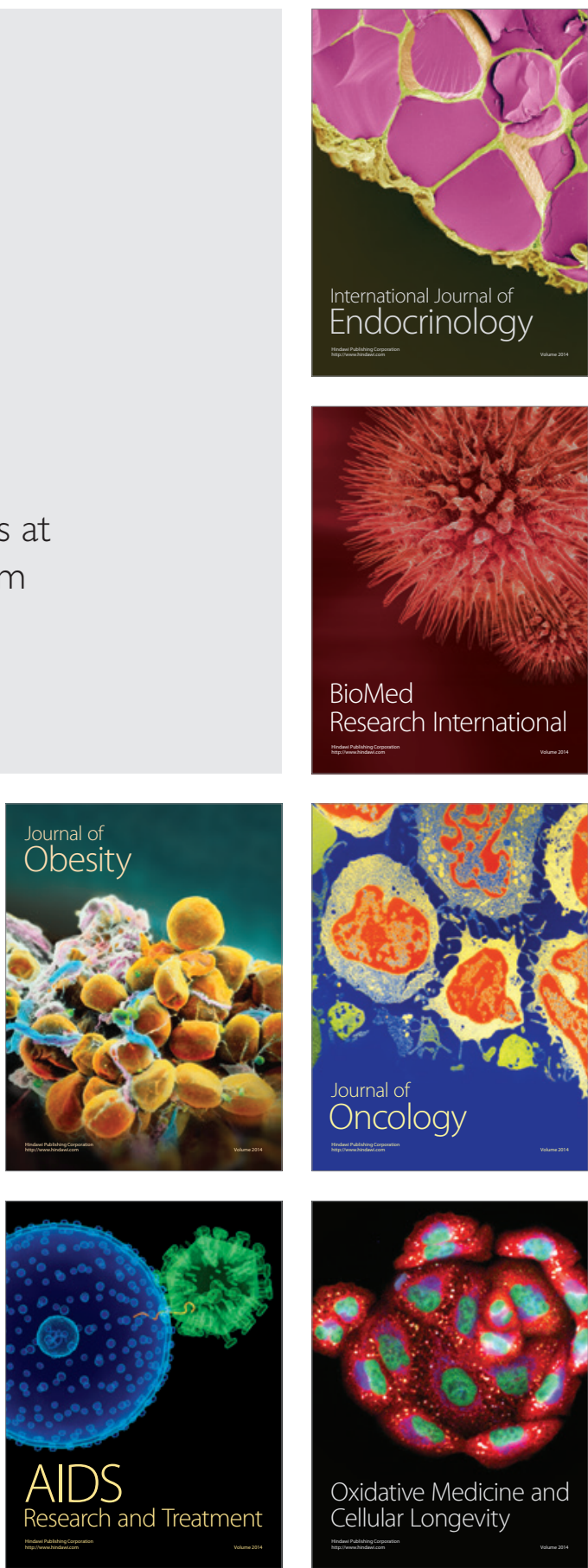